Session

\title{
Use of Lab Experiments to Build Transport Concepts
}

\author{
Anna Siemionko and Nam K. Kim \\ Department of Chemical Engineering \\ Michigan Technological University \\ 2003 ASEE Annual Conference \\ Nashville, Tennessee
}

\begin{abstract}
One of the difficult concepts to teach in junior students' class is momentum transport. Derivation of Bernoulli equation is one of the first equation products from the momentum balance that can be used in many flow evaluations. Use of the equation to specific situation of various fluid flows will require knowledge of friction losses, flow rate measurement by means of orifice flow meter, and rotameter. Calibration of an orifice meter requires use of a manometer that allows us to measure the difference in fluid pressures. The differential pressures are transduced into the current signals that can be easily interfaced by the computer through the acquisition board.

The foundation of flow rate measurements is pail and scale method for our water flow system. The water-receiving tank is sat on a built-in accurate electronic scale so that the precise flow rate can be measured with a stopwatch. Each week experiments will calibrate one instrument at a time so that they begin to build their confidence on the instruments. They understand with confidence the flow system because they confirm by themselves the accuracy of orifice meter as well as rotameter.
\end{abstract}

The friction losses in a straight copper tube can be calculated based on the Bernoulli equation and these values are checked by actual measurement of differential pressures between the two points. This also allows them to compute the orifice coefficients and see why this parameter has to exist. The friction losses due to a sudden expansion or contraction or fittings in the line can be calculated and confirm with actual measurements. These experiments help them to understand the friction losses due to entire piping system and enable them to construct a system curve on the pumping diagram to find an operating point.

Once these concepts are developed, the computer data acquisition system will help them in bookkeeping the data against time. At this point students fully appreciate the roles of the flow instruments and the computer. 


\section{Introduction}

One of the more difficult concepts to teach to students is momentum transport. Many students feel that sitting in a lecture and learning the theory is not the most effective way to learn momentum concepts. Therefore, a junior level transport lab has been develop in the Chemical Engineering Department of Michigan Technological University to teach basic momentum transport through physical experiments and data acquisition.

The laboratory consists of several experiments that build upon themselves and convey to the students the concept of momentum transport, specifically frictional losses. The first experiment deals with the construction of a P\&ID diagram of the process, followed by an exercise that determines viscosity of various concentrations of a sugar/water solution. Following that is an experiment for the determination of differential pressure, which is trailed by fluid velocity measurements and Reynolds number calculations. Following the fluid velocity measurements, the students perform an experiment that deals with frictional losses in a straight length of pipe, which is followed by a pumping analysis of the entire system. In all, each experiment shows the students an aspect of momentum transport that would not have been conveyed through just a lecture. The experiments focus on frictional losses and how different characteristics of fluids affect the flow in the process.

\section{Process Piping and Instrumentation Diagram (P\&ID)}

Upon seeing a chemical process for the first time, most students feel intimidated and anxious until they become familiar with it. One way for students to become familiar with any process is to create a piping and instrumentation diagram (P\&ID). A P\&ID is a two-dimensional drawing of a process with the relative positions of each instrument, pipe, fitting, etc., is shown but not to scale. Figure 1 below shows a P\&ID of the junior level transport laboratory. The symbols for the instruments and fittings used are suggested by the Microsoft Visio program, but there are other symbols as published by Chemical Engineering, "Effective Communication for Engineers", McGraw-Hill, 1974; Bechtel Corporation, Piping Legend". Therefore, the first experiment that the students perform in the junior transport lab is creating a P\&ID diagram of the laboratory setup. The P\&ID shows them that a three dimensional process can be represented on a single piece of paper. For this assignment, the students are exposed for the first time to the lab bench system. They draw and sketch the system on a piece of paper and get familiar with this system along the way. They are required to start sketching at one point and follow the process through all the piping and instrumentation until they end at their original starting point. While doing this, they take note of every process instrument and valve along the way, which familiarizes them with all instrumentation within the system. This is a great way for them to get familiar with the lab set up before running any experiments. After completion of their P\&ID, the students feel that it is an efficient way to represent any system, feel more comfortable with the process and are 
not as intimidated by it as before.

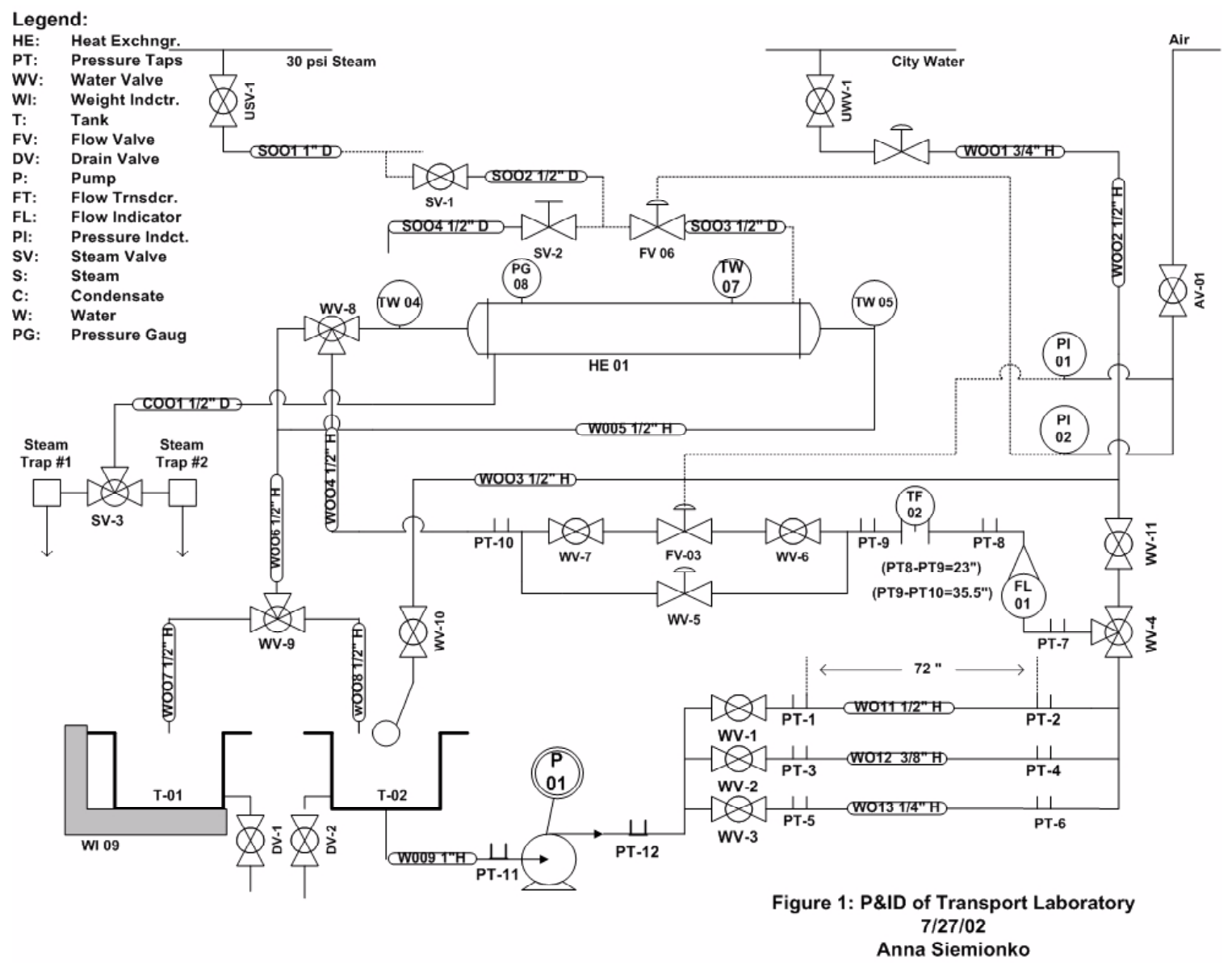

Figure 1: P\&ID of Transport Laboratory

\section{Viscosity Measurement}

The second experiment the students perform in the transport lab is the viscosity experiment. This introduces the students to the concept of viscosity and how it is affected by concentrations. The lecture to the laboratory explains to the students of the methods of measuring viscosity using the rotating concentric cylinder and capillary flow methods. The lecture is focused on the capillary method, since Cannon-Fenske viscometers are used in the laboratory. The lecture begins by explaining to the students the concept of shear stress between fluid layers in laminar flow and the velocity gradient. The Hagen-Poiseuille equation is introduced as well to help relay the theory of viscosity by measuring the pressure drop and the velocity of the liquid in a capillary. The students become familiar with the formulation of the Hagen-Poiseuille equation and how it relates to the viscosity measurements. For the Cannon-Fenske viscometer used in the laboratory, the viscometer constant incorporates the pressure

Proceedings of the American Society for Engineering Education Annual Conference \& Exposition 
drop between the two reservoirs as well as the diameter of the reservoir, so that the only data collected by the students is the time it takes for the liquid to flow from one reservoir to the other.

The class is divided into various groups and each group has an assigned concentration of sucrose and water varying from $10 \%$ to $65 \%$ sucrose. The viscosity is measured with a specific Cannon-Fenske viscometer, which depends on the concentration used, and each group shares their data with the rest of the class. Since viscosity is also a function of temperature, the viscometers are placed in a constant temperature water bath of $40^{\circ} \mathrm{C}$ and remain within the bath until all data is acquired. The viscometer stays in the water bath for the duration of all the students' trials to ensure that all data taken is at the same temperature.

The data analysis includes a statistical analysis of the data for the mean, variance and percent error between acquired data and literature values. A sample of the data acquired can be seen below in Figure 2 . In this figure, it is seen that up to $50 \%$ concentration, the published and literature values match quite nicely. However, there are significant discrepancies observed as the sucrose concentration increases over $50 \%$. One possibility for this is the evaporation of water while the temperature of the solution increases in the constant water bath. For concentration of above $50 \%$, small differences in the amount of water will sway the concentration forward or backward, depending on if water is added or removed. Since the solutions were heated to $40^{\circ} \mathrm{C}$, it is very possible that water had evaporated and raised the concentration of the solutions.

After the data collection and analysis, the students individually create a curve between the concentration and viscosity. This is a basic experiment that teaches the students the effect of concentration, temperature and density on viscosity and how it plays a part in momentum transport. They learn that the transport of shear stress between fluid layers in laminar flow will affect how fluids of different viscosities move in process piping and equipment. This experiment and lecture also begins to teach the students how viscosity affects the friction losses through the Fanning friction factor for straight pipe by foreshadowing experiments in the future. The students begin to realize that viscosity plays a major role in the behavior of fluids. 


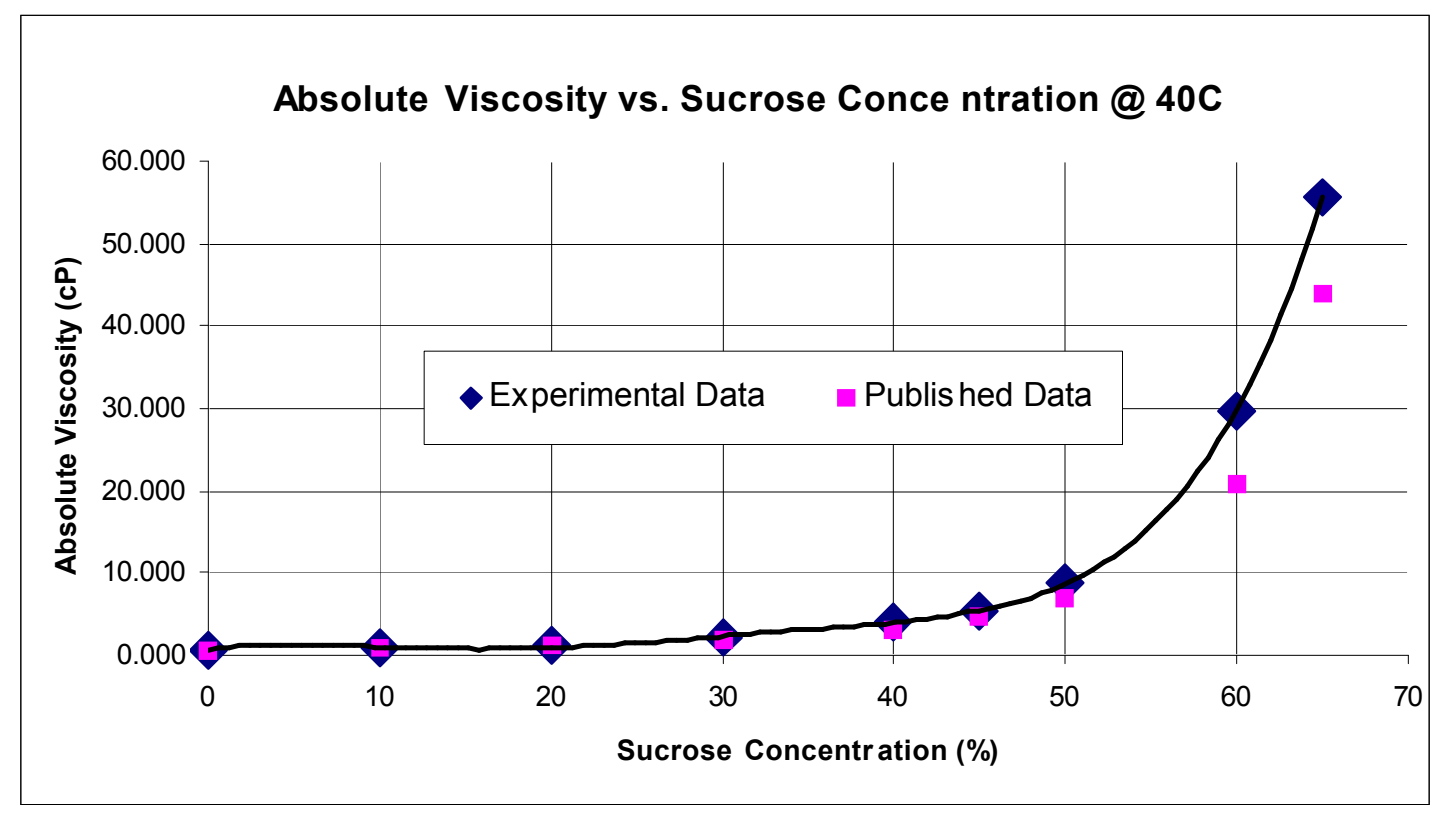

Figure 2: Sample Plot of Viscosity Experiment Results

\section{Differential Pressure Measurement}

Frictional losses in flowing fluid are related to the pressure drop through the Fanning friction factor. This concept is introduced in the lecture in hopes that the students will learn how the pressure drop affects the frictional losses and the student's understanding of pressure drop through piping is imperative for them to understand how fluid flow is affected. Thus, an introductory experiment in the transport laboratory is to calibrate the differential pressure transducer before making any differential pressure measurements. This is their first introduction to calibration of instrumentation and this calibration is the first they perform. This is one of the most important experiments done in this laboratory because all subsequent experiments require the use of the calibration curve that this assignment produces.

The calibration of the DP transducer is done with a specifically designed manometer filled with an organic fluid with a density of $1.725 \mathrm{~g} / \mathrm{ml}$. The manometer is designed so that the transducer pressure taps can be directly inserted into the manometer and a corresponding current signal given, depending on the height difference. The students calibrate the transducer by physically applying pressure to one side of the manometer and measuring the difference in heights between the high and low pressure sides. Knowing the density of the fluid, the height differences can be converted to a differential pressure and each differential pressure has its own corresponding current signal.

The final product of the experiment is a calibration curve that relates the differential 
pressure to the current signal. A regression equation is calculated and used is subsequent calculations. The calibration of the pressure transducer emphasizes to the students the importance of calibration of any instrument in acquiring measurement. Figure 3 shows actual calibration data taken in the laboratory.

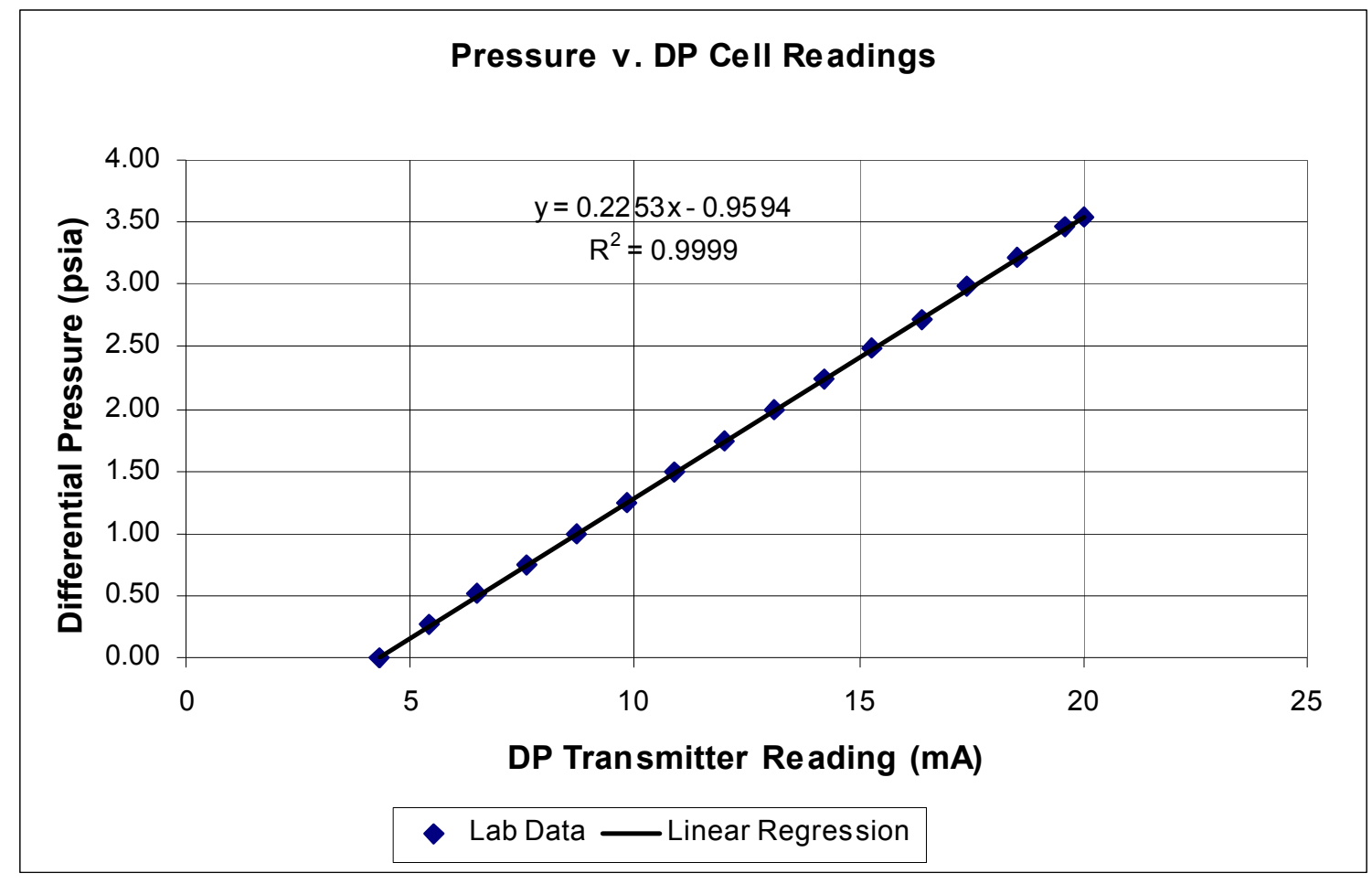

Figure 3: Differential Pressure Transducer Calibration Curve

\section{Fluid Velocity and Reynolds Number}

The next experiment in the sequence has the students calibrate the rotameter using the pail and scale method. In the lecture, the theory behind a rotameter is covered as well as an introduction to fluid flow and different flow characteristics. The Reynolds number is introduced and the Osborne Reynolds experiment is explained. In the lecture, it is also explained how the Reynolds number is affected by the viscosity through the Fanning friction factor. Thus, it is essential for the students to understand the importance of the Reynolds number and what it signifies in fluid dynamics.

For this task, the pail and scale method is used to measure the mass flow rate, where students weigh the amount of water coming out of the system in a definite amount of time. The water is directed through three different pipe sizes (1/2", 3/8", 1/4") at different rotameter settings and the exiting water is measured on an electronic balance with an accuracy of $.001 \mathrm{~kg}$. The rota meter settings range from $10 \%-70 \%$ for each individual pipe size. The experimental data consists of the rotameter setting, the weight of water out of the system in a known amount of time and the temperature of the 
water. From the temperature data, the students can find the corresponding viscosity and density. The mass and time of the water is used to convert the mass flow rate into a volumetric flow rate.

The data analysis for this experiment includes the calculation of the fluid velocity through the pipes. The final calculation the students perform is to calculate the Reynolds number and identify the flow, whether it is laminar, turbulent or transitional. This shows the students how laminar, turbulent and transitional flows physically look as its coming out of the exit pipe. The students create a calibration curve for the rotameter and use the regression equation in later experiments. Figure 4 shows a calibration curve constructed in the laboratory.

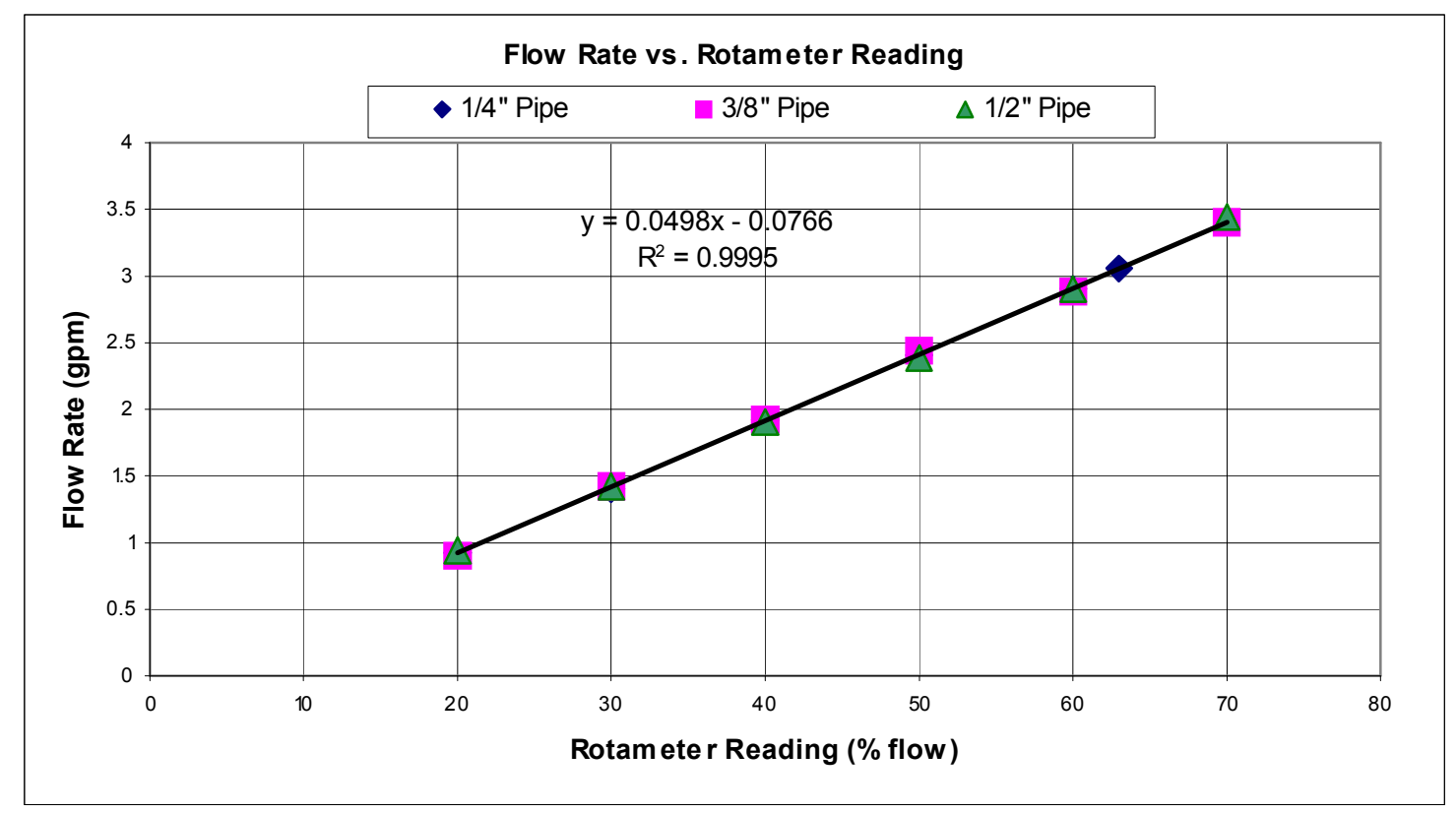

Figure 4: Rotameter Calibration Curve

\section{Frictional Losses}

The most difficult part of momentum transport that students have a problem with are the frictional losses. It is hard for them to understand frictional losses because they don't physically see them. One experiment done in the transport laboratory is the measurement of the frictional losses across a straight length of pipe. In the class lecture, the students are introduced to the mechanical energy balance, it is simplified, and the final working equation is shown below: 


$$
\Delta\left(\frac{\mathrm{P}}{\rho}\right)+4 \mathrm{f} \frac{\mathrm{L}}{\mathrm{D}}\left[\frac{1}{2} \frac{\left(\mathrm{v}_{\text {avg }}\right)^{2}}{\mathrm{~g}_{\mathrm{c}}}\right]=0
$$

Eq. 1

In the experiment, the students measure the pressure drop across a known length and diameter of straight pipe. The pressure taps from the differential pressure transducer are inserted into the pipe and a rotameter percentage is set. From the rotameter calibration curve, the volumetric flow rate can be determined. Once that is accomplished, a current signal is given off and the students use their calibration curve for the differential pressure transducer to determine the pressure drop. This procedure is done for a known length of straight pipe and three different diameter pipes (1/2", 1/4", $3 / 8$ ").

The data analysis for this experiment consist of comparing the measured frictional losses from the differential pressure transducer to the calculated frictional losses based on the definition of frictional losses in a straight pipe. The students perform the calculation and compare the measured and calculated frictional losses. This experiment allows the students to physically measure the amount of friction within a straight length of pipe and better to understand it. Figure 5 shows a plot of the measured and calculated frictional losses for three pipe sizes.

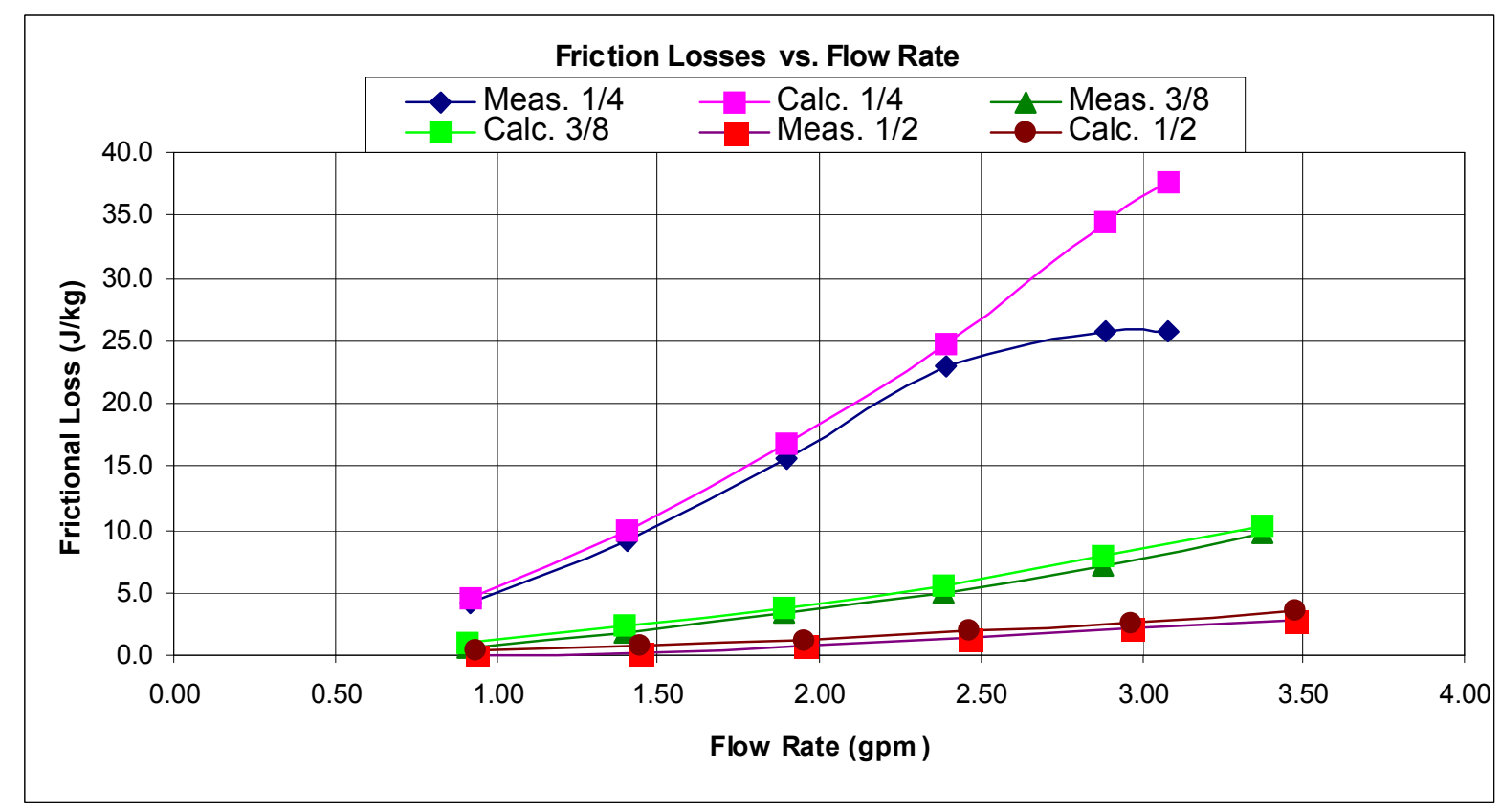

Figure 5: Measured and Calculated Frictional Losses in a Straight Pipe

\section{Pumping System Analysis}

In the preceding section, the students measured the frictional losses for a straight 
length of pipe. In this experiment, they take into account not just the straight pipes, but also everything else within the system. This includes valves, fittings, expansions, contractions and all other instrumentation within the system.

Once again the mechanical energy balance is used, however, only the shaft work term is deleted, since no mechanical energy is being added to the system. The simplified energy balance is performed on both the discharge and suction sides of the pump. By adding the terms from the discharge and suction sides, an overall equation is composed that relates the total head ( $\mathrm{ft}$ of water) to the volumetric flow rate.

$$
H_{D}-H_{s}=z_{2}-z_{1}+\frac{8 Q^{2}}{\pi^{2} g}\left[\frac{1+4 f_{D} \frac{L_{D}}{D_{D}}+\Sigma K_{D}}{D_{D}^{4}}+\frac{4 f_{s} \frac{L_{s}}{D_{s}}+\Sigma K_{s}}{D_{s}^{4}}\right]
$$

Since the terms for the velocity head and potential head can be determined from previous experiments at different volumetric flow rates, the students assignment is to calculate the SK term within the SF term within the mechanical energy balance as well as develop an operating point of the system on the pump curve.

For this experiment, the students physically count the elbows, tees, contractions, valves, expansions and other instrumentation within the entire system. They also measure the entire length of straight pipe that is contained by the fittings and valves. In order to determine how the fittings affect the system, the students identify the equivalent number of velocity heads for each piece of the system from published literature. The data from the fittings and straight length of pipe is tabulated and a total discharge head is calculated. Since Equation 6 is dependent upon Q, the volumetric flow rate, the students use the data from the rotameter calibration in assigning a value for $\mathrm{Q}$.

For different values of $Q$, the students get a different value for the total discharge head. This plot along with a characteristic pump curve provides an operating point of the system. Table 1, below, shows the data collected in the laboratory, where all fittings, valves and instrumentations are accounted for through the number of velocity heads. Figure 6 shows the calculated pumping system curve overlaid on the pump characteristic curve. The pump characteristic curve in the figure is a simplification of the full pump curve since the total volumetric flow rate of the system is a maximum of 4 gallons per minute. By simplifying the curve, the operating point is more prominent and easier to identify. The students identify the operating point of the system and learn that the pump has to overcome a lot of feet of head in order to perform up to its specifications. 
Table 1: Tabulated Instrumentation and Corresponding Velocity Heads

\begin{tabular}{|c|c|c|c|c|c|c|c|}
\hline & & \multicolumn{3}{|c|}{ Suction Line } & \multicolumn{3}{|c|}{ Discharge Line } \\
\hline & & No. & $\mathbf{k}$ & Total & No. & $\mathbf{k}$ & Total \\
\hline \multirow[t]{14}{*}{ 1/2" Pipe } & Straight Pipe & - & - & - & - & & $278.3125 \mathrm{in}$. \\
\hline & Ball Valve & - & - & - & 3 & 0.25 & 0.75 \\
\hline & 3-way Valve & - & - & - & 3 & 0.50 & 1.50 \\
\hline & Control Valve & - & - & - & 1 & 48.00 & 48.00 \\
\hline & & & & & & & \\
\hline & $90^{\circ}$ Elbow & - & - & - & 8 & 0.75 & 6.00 \\
\hline & $\begin{array}{l}\text { Tee (along } \\
\text { run) }\end{array}$ & - & - & - & 5 & 0.40 & 2.00 \\
\hline & Tee (as elbow) & - & - & - & 1 & 1.50 & 1.50 \\
\hline & Expansion & - & - & - & 11 & 0.59 & 6.50 \\
\hline & Contraction & - & - & - & 11 & 1.15 & 12.70 \\
\hline & Coupling & - & - & - & 1 & 0.04 & 0.04 \\
\hline & Pressure Tap & - & - & - & 7 & - & 0.00 \\
\hline & Rotameter & - & - & - & 1 & 25.00 & 25.00 \\
\hline & Orifice Plate & - & - & - & 1 & 190.00 & 190.00 \\
\hline \multirow[t]{5}{*}{ 1" Pipe } & Straight Pipe & - & - & $37.25 \mathrm{in}$ & - & & $11.5 \mathrm{in.}$ \\
\hline & $90^{\circ}$ Elbow & 3 & 0.75 & 2.25 & - & - & - \\
\hline & Coupling & 2 & 0.04 & 0.08 & 1 & 0.04 & 0.04 \\
\hline & Pressure Tap & 1 & - & 0.00 & 1 & - & 0.00 \\
\hline & Contraction & - & - & - & 1 & 0.51 & 0.51 \\
\hline & & & $\Sigma \mathbf{K}$ & 2.33 & & & 294.55 \\
\hline
\end{tabular}




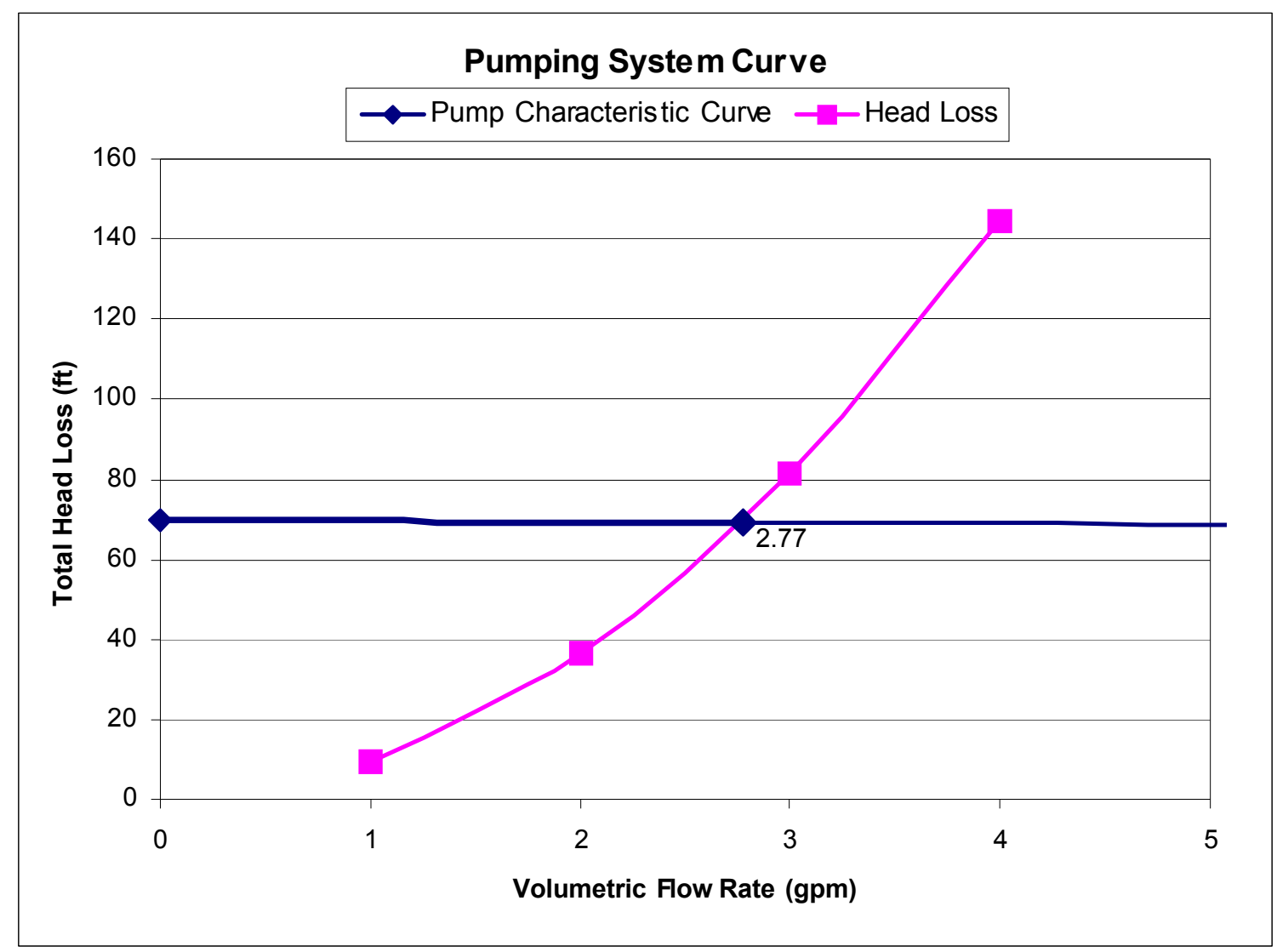

Figure 6: Pumping System Curve

\section{Discussion}

The lab sessions where these experiments were performed were held in a laboratory specifically designed for these trials and measurements. The lab consisted of eight identical stations and each stations held a group of two students. The students performed the assigned experiments with the help of their group member; however, the final reports were performed individually.

The lab sessions were two hours long, held after the corresponding lecture. In the lecture, the background material was covered as well as different examples presented. This gave students and introduction to the experiment that they would be performing during that week. This particular set of experiments shows the students how factors affect frictional losses and fluid flow. Each experiment teaches them a new phenomenon and all experiments are put into use when the pumping system experiment is performed. In this last experiment, the data from all subsequent experiments is used and the students put everything they learned into analyzing the pumping system.

The reports for the experiments were prepared in a memo format where several 
section headings were required. Those sections were an introduction, data and results, discussion and conclusion. The introduction section was required to have some background information on the theory behind the experiment as well as an opening to the experiment performed. The data and results section was required to have data pertinent to the experiment and presented in an appropriate format. The discussion section was used for explaining the data and results and the conclusion section required that the summary of the entire experiment. The memo had a maximum page requirement of two pages and the students had the task of organizing the data and discussion to fit the al lotted format. This taught the students how to organize and manage their writing so that the maximum allotment was not exceeded.

\section{Conclusion}

The junior level Transport Laboratory at Michigan Technological University has developed several experiments to teach students about momentum transport, since it is one of the most difficult things for students to envision and learn. By having students perform basic experiments, the idea of momentum transport is more easily conveyed and understood.

The experiments in the laboratory deal with teaching the different aspects of momentum and how different factors affect it. The students learn to create a P\&ID of a piping process as well as learn how temperature and concentration affect viscosity. The students also perform experiments that show them how differential pressures within a straight pipe affect the frictional losses and how the frictional losses are related to fluid flow and the Reynolds number. The students also learn how to calibrate a differential pressure transducer as well as a rotameter and gain knowledge of why calibration is crucial in acquiring data. All these experiments help them to understand the friction loses due to the entire piping system and enable them to construct a system curve on the pumping diagram to find the operating point of the system.

Overall, this laboratory gives the students an opportunity to experience chemical engineering first hand. They have the chance to operate their own lab bench scale system and practice using instrumentation that is used in full-scale chemical operations.

\section{References}

Kim, N.K., "CM3215 Transport Laboratory Manual", Department of Chemical Engineering, Michigan Technological University, 2002.

Felder, R.M. and Rousseau, R.W. "Elementary Principles of Chemical Processes", $3^{\text {rd }}$ ed. New York: John Wiley \& Sons, 2000.

Geankoplis, C.J. "Transport Processes and Unit Operations". $3^{\text {rd }}$ ed. New Jersey: Prentice Hall, 1993. 


\section{Acknowledgement}

We are grateful to James and Sally Brozzo (MTU 1953) for their generous financial contribution to this new lab. Nam Kim and Kirk Schulz contributed in designing the initial draft of processes to be built. Dave Caspary developed the blue print and supervised installation process. Jerry Norkol and Tim Gasperich performed the construction. Romulo Almedia, David Caspary, Nicholas Greenland, Jaya Yaddanapudi, Jason Keith, and Anna Siemionko contributed the initial operating part of the manual.

\section{Authors}

Anna Siemionko

Anna Siemionko is a graduate student in Chemical Engineering at Michigan Technological University and has served as a GTA for the Transport Laboratory for 2 semesters. She is from Walled Lake, MI and received her B.S. in Chemical Engineering from Michigan Technological University in 2001. She is a member of the American Institute of Chemical Engineers, American Chemical Society and President of the Aquanauts SCUBA Club of Michigan Tech. (Email: asiemion@mtu.edu)

\section{Nam K. Kim}

Nam Kim is an associate professor of chemical engineering at Michigan Technological University. He was involved in the process of developing this lab. He teaches process control theory and process control laboratory courses at Michigan Tech. Kim does research in the area of advanced process control (adaptive and interacting multi-variables, statistical process control, fuzzy logic, and neural networks) and energy conservation and optimization. He has a Ph.D. from Montana State University in chemical engineering. (Email: kimnk@mtu.edu) 